\title{
Psychoactive Substances and How to Find Them: Electrochemiluminescence as a Strategy for Identification and Differentiation of Drug Species
}

\author{
Kelly Brown ${ }^{1}$, Pamela Allan ${ }^{1}$, Paul S. Francis ${ }^{2}$ and Lynn Dennany ${ }^{1, z}$ \\ ${ }^{1}$ WestCHEM Department of Pure and Applied Chemistry, University of Strathclyde, \\ Technology and Innovation Centre, 99 George Street, Glasgow, G1 1RD, UK \\ ${ }^{2}$ School of Life \& Environmental Sciences, Deakin University, Waurn Ponds, Victoria, \\ 3216, Australia \\ ${ }^{z}$ lynn.dennany@strath.ac.uk
}

The rapid and continued appearance of novel psychoactive substances onto the global drug market continues to highlight the need for the introduction of novel screening methodologies. Here we discuss the potential of electrochemiluminescence (ECL)-based sensors as viable alternatives to address this current gap within forensic practices. By utilizing a variety of luminophores, differences within the mechanisms responsible for luminescence can be exploited providing the potential to identify different drug species that possess similar structural characteristics. Using a combination of iridium-, osmium- and ruthenium-based sensors, a strong proof of concept for not only the utilization of ECL sensors for drug screening but also the development of multi-metal sensing systems has been demonstrated. 


\section{Introduction}

Despite the implementation of increased legislative controls, the use of novel psychoactive substances (NPS) remains prevalent across the global drug market. NPS are typically designed to mimic the effects of traditional illicit substances but possess altered chemical structures to place them outside legislative control. As a direct result of their accessibility and falsely perceived safety, they have grown in popularity amongst users. ${ }^{1-3}$ Despite the historical use of presumptive tests as a screening tool, they have been found to be inadequate for many NPS, and they are vulnerable to interferences. The current technologies offered in place of these presumptive tests, however, suffer from high outlay, maintenance and operational costs. ${ }^{4-7}$ Moreover, their use is restricted to fully equipped laboratory facilities. Electrochemiluminescence (ECL) offers a feasible solution towards bridging this current gap within screening methodologies. ECL is a powerful analytical technique that has seen an increase in its development and applications in recent years. ECL and other electrochemical (EC) based techniques are becoming increasingly popular for "in-field" and point-

of-care applications, with numerous benefits over the more traditional techniques. ${ }^{8-20}$ Primarily, ECL and EC can be performed with simple instrumentation. Portable ECL equipment is commercially available, with some even incorporating Bluetooth functionality allowing real-time monitoring by smart phone devices. Moreover, their increased operational simplicity, rapid analysis times, improved sensitivity and minimal sample preparations sees ECL sensors well suited to "infield" applications, reducing the demand for expertise in order to perform measurements.

Traditional ECL systems typically employ a single ruthenium-based luminophore. However, this single luminophore approach often prevents the successful differentiation of structurally similar compounds, which typically interact with the complex via analogous mechanisms producing emission within the same potential regions. ${ }^{11,21,22}$ Employment of multi-luminophore sensors utilising several different metal complex luminophores as well as $\mathrm{pH}$-controlled emission offer viable approaches to tackle the limited specificity associated with ECL techniques. Prior work has demonstrated the ability to exploit differences in the relationship between $\mathrm{pH}$ and luminescence intensity, to produce a system whereby two structurally similar species, atropine and scopolamine, could both be identified within a mixed sample. ${ }^{21}$ This involved an "emission-on/emission-off" system, whereby sample $\mathrm{pH}$ was adjusted to prevent emission from atropine, whilst recording that of scopolamine. ${ }^{21}$ Although this initial study showed promise, it relied upon an in-depth knowledge and understanding of the relationship between the target analytes ECL signal with $\mathrm{pH}$. 
The employment of luminophores based on other metals, such as iridium and osmium, offers possibility to further increase specificity, with each metal providing different selectivity. Prior works have successfully demonstrated the ability of iridium and osmium metal complexes to act as effective luminophores for both annihilation and co-reactant ECL. ${ }^{23-32}$ Previous studies have mostly involved tri- $n$-propylamine (TPA), the workhorse of anodic co-reactant ECL, with iridium and osmium complexes producing efficiencies comparable or indeed superior to those of the traditional $\left[\mathrm{Ru}(\mathrm{bpy})_{3}\right]^{2+}$ luminophore. ${ }^{23-32}$ To date, a range of illicit and alternative drug substances have been detected down to forensically and clinically relevant ranges via ECL, including atropine ${ }^{21,22,33-36}$, scopolamine ${ }^{21,37}$, ketamine ${ }^{38}$, amphetamine-type stimulants (ATS) ${ }^{11}$ and cocaine. ${ }^{34,39-45}$ However, few investigations into the detection of multiple analytes within the same sample matrix have been performed, due to the inherent lack of specificity offered by ECL This is problematic for the screening of typical street samples that may contain a variety of structurally related drugs, in addition to diluents or adulterants. A large number of NPS contain amines that produce ECL with $\left[\mathrm{Ru}(\mathrm{bpy})_{3}\right]^{2+}$ within the same potential region, and cannot be reliably differentiated from one another, restricting identification to high level functional group classification. ${ }^{46}$ As such, single luminophore ECL is not suited as an in-field screening method.

Using a combination of different metal complex luminophores (or multi-metal arrays), differentiation between structurally similar species becomes possible. By employing this strategy, we have successfully demonstrated the detection of different structurally similar species, whilst negating the interference from naturally occurring amino acids present within biological matrices (a previously noted limitation for the use of $\mathrm{ECL}^{37,46-50}$ ). The wider employment of such a methodology will only stand to improve the performance and widen the applications of ECL.

\section{Experimental}

\section{$\underline{\text { Reagents and Materials }}$}

(-)-Scopolamine hydrobromide trihydrate, atropine sulfate, methamphetamine (MA), 3,4methylenedioxymethamphetamine (MDMA), lithium perchlorate $\left(\mathrm{LiClO}_{4}\right)$ and $117 \mathrm{Nafion}(\sim 5 \%$ mixture of lower aliphatic alcohols and water) were purchased from Sigma-Aldrich. Acetonitrile (purchased from Scharlau) was distilled over calcium hydride under a nitrogen atmosphere and collected as required. The $\left[\operatorname{Ir}(\mathrm{bt})_{2}(\mathrm{pt}-\mathrm{TEG})\right]^{+}$and $\left[\mathrm{Os}(\mathrm{diars})_{2}(\mathrm{bthp})\right]^{2+}$ were prepared as chloride and 
hexafluorophosphate salts, respectively, according to previously published procedures ${ }^{51-54}$ All aqueous samples were prepared with Milli-Q $\left(18 \mathrm{~m} \Omega \mathrm{cm}^{-1}\right)$.

Instrumentation

Electrochemical measurements were performed using a Metrohm Autolab PGSTAT204 or PGSTAT128N potentiostat, with GSI Technologies Electrochemical carbon screen printed electrodes (SPE) with a $4 \mathrm{~mm}$ carbon working electrode, carbon counter electrode and Ag paste quasi-reference electrode with a maximum of $100 \mu \mathrm{L}$ sample volume. All ECL measurements were performed within a light-tight Faraday cage with an ET Enterprises $29 \mathrm{~mm}$ 9828B photomultiplier tube (PMT) positioned directly above the working electrode surface using a specially designed sensor holder.

\section{Sensor Fabrication}

The carbon paste working electrode surface was modified through the drop-casting process previously optimised for $\left[\mathrm{Ru}(\mathrm{bpy})_{3}\right]^{2+21,22,37}$ and involves preparation of a Nafion based film containing a final concentration of $0.5 \mathrm{mM}$ of the complex $\left(\left[\operatorname{Ir}(\mathrm{bt})_{2}(\mathrm{pt}-\mathrm{TEG})\right]^{+}\right.$or $\left[\mathrm{Os}(\text { diars })_{2}(\mathrm{bthp})\right]^{2+}$ ) encapsulated within a $0.2 \%$ Nafion film. A $1 \mathrm{mM}$ stock of each complex was prepared in 50:50 $\mathrm{H}_{2} \mathrm{O}$ :acetonitrile and mixed in a 1:1 v/v ratio with a $0.4 \%$ Nafion stock, also prepared within acetonitrile. Once prepared, the film was stored at room temperature under darkness to prevent photodegradation. In order to prevented degradation of the carbon paste working electrode, drop casting of $7 \mu \mathrm{L}$ of the film to the working electrode surface was immediately followed with the application of heat to evaporate any residual acetonitrile, preventing electrode destruction, while securing the complex to the electrode surface. 


\section{Results and Discussion}

As a preliminary examination of the ability of different film-encapsulated metal-complex electrochemiluminophores $\left(\left[\operatorname{Ru}(\mathrm{bpy})_{3}\right]^{2+}, \quad\left[\mathrm{Os}(\mathrm{diars})_{2}(\mathrm{bthp})\right]^{2+}\right.$ and $\left.\left[\operatorname{Ir}(\mathrm{bt})_{2}(\mathrm{pt}-\mathrm{TEG})\right]^{+}\right)$to distinguish between structurally related compounds of forensic importance, we initially selected methamphetamine (MA) and 3,4-methylenedioxymethamphetamine (ecstasy; MDMA) as coreactants. These amphetamine type stimulants (ATS) have previously been detected using electrochemical methods including ECL. ${ }^{11,55-60}$ Although both MA and MDMA are classified as secondary amines, refer to Figure 1, previous interrogation of their electroactivity has demonstrated alternative behaviors with regard to their electrochemistry, as was observed here. ${ }^{61}$

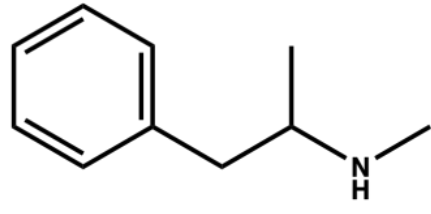

MA

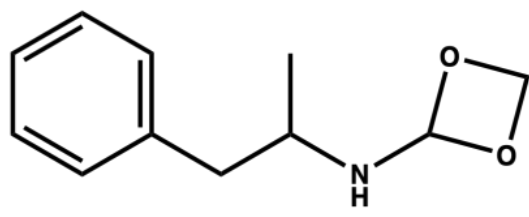

MDMA

Figure 1. Chemical Structures of methamphetamine (MA) and methylenedioxymethamphetamine (MDMA)

Interrogation of the electrochemical behavior of MDMA with carbon paste screen-printed electrodes (SPE) revealed an oxidation peak at $\sim 0.95 \mathrm{~V} v s \mathrm{Ag} / \mathrm{Ag}^{+}$, but MA displayed no oxidation in this potential region (Figure 2 (a)). This is comparable to previously observed trends, were the occurrence of the oxidation peak for MDMA can be attributed to the methyldioxy group, gifting it enhanced electroactivity over MA. ${ }^{61}$ The lower electroactivity of MA requires the application of greater anodic potentials to produce the oxidative form of this secondary amine. Despite application of potentials up to $1.6 \mathrm{~V}$ vs $\mathrm{Ag} / \mathrm{AgCl}$ oxidation at unmodified carbon electrodes has not been achieved. ${ }^{62}$ Although oxidation of MA has previously been achieved, it required the use of platinum electrodes which can reliably operate within this higher potential window with no determinant toward the electroactive surface. ${ }^{61}$ Despite this difference in electrochemical behavior, both MDMA and MA produced comparable ECL signals with $\left[\mathrm{Ru}(\mathrm{bpy})_{3}\right]^{2+}$ across the same potential region (Figure 2 (b)), at a physiological $\mathrm{pH}$ of 7 . This correlates well with previous studies that have demonstrated ECL signals across the same potential region for both species with the $\left[\mathrm{Ru}(\mathrm{bpy})_{3}\right]^{2+}$ luminophore. The ECL signals typically observed differ in intensity but are not sufficiently distinct enough to facilitate reliable identification of the individual ATS. ${ }^{11,61}$ In contrast, both MDMA and MA were found to quench the large intrinsic 'blank' ECL signal produced by the 
film-encapsulated $\left[\mathrm{Os}(\text { diars) })_{2}(\text { bthp) }]^{2+}\right.$ complex (for example, see the quenching by MDMA in Figure $2(\mathrm{c}))$. The $\left[\mathrm{Os}(\text { diars })_{2}(\mathrm{bthp})\right]^{2+}$ complex is observed to produce a large intrinsic signal in the absence of any co-reactant. This inherent signal may be attributed to bond-breakage within the luminophore framework, energetic enough to populate the emissive state, although on-going research to decipher the exact mechanism are currently ongoing. ${ }^{31,51,63-66}$ This behavior is in contrast to either of the ruthenium or iridium complexes within this study but provides the unique opportunity to utilize a quenching mechanism upon which the presence of target analytes can be determined. Although the inability to distinguish between the two ATS compounds remains, the contrasting behavior with ruthenium and iridium luminophores could be utilized within a multiluminophore array. Although the influence upon the ECL signal of these two luminophores was different, in each case the two ATS compounds exhibited very similar behavior and therefore could not be distinguished.

Interestingly, ECL was observed for MDMA with the film-encapsulated $\left[\operatorname{Ir}(\mathrm{bt})_{2}(\mathrm{pt}-\mathrm{TEG})\right]^{+}$, whilst MA was indistinguishable from the intrinsic blank signal obtained in the absence of any coreactants $^{21,22,37,67-69}$, as shown in Figure 2 (d). As such, this iridium-based complex offers the opportunity to distinguish between the two stimulants. Moreover, the markedly different ECL behavior of the co-reactants with these three encapsulated metal complexes demonstrates the potential to develop array-based screening tools for the selective identification of illicit substances. 

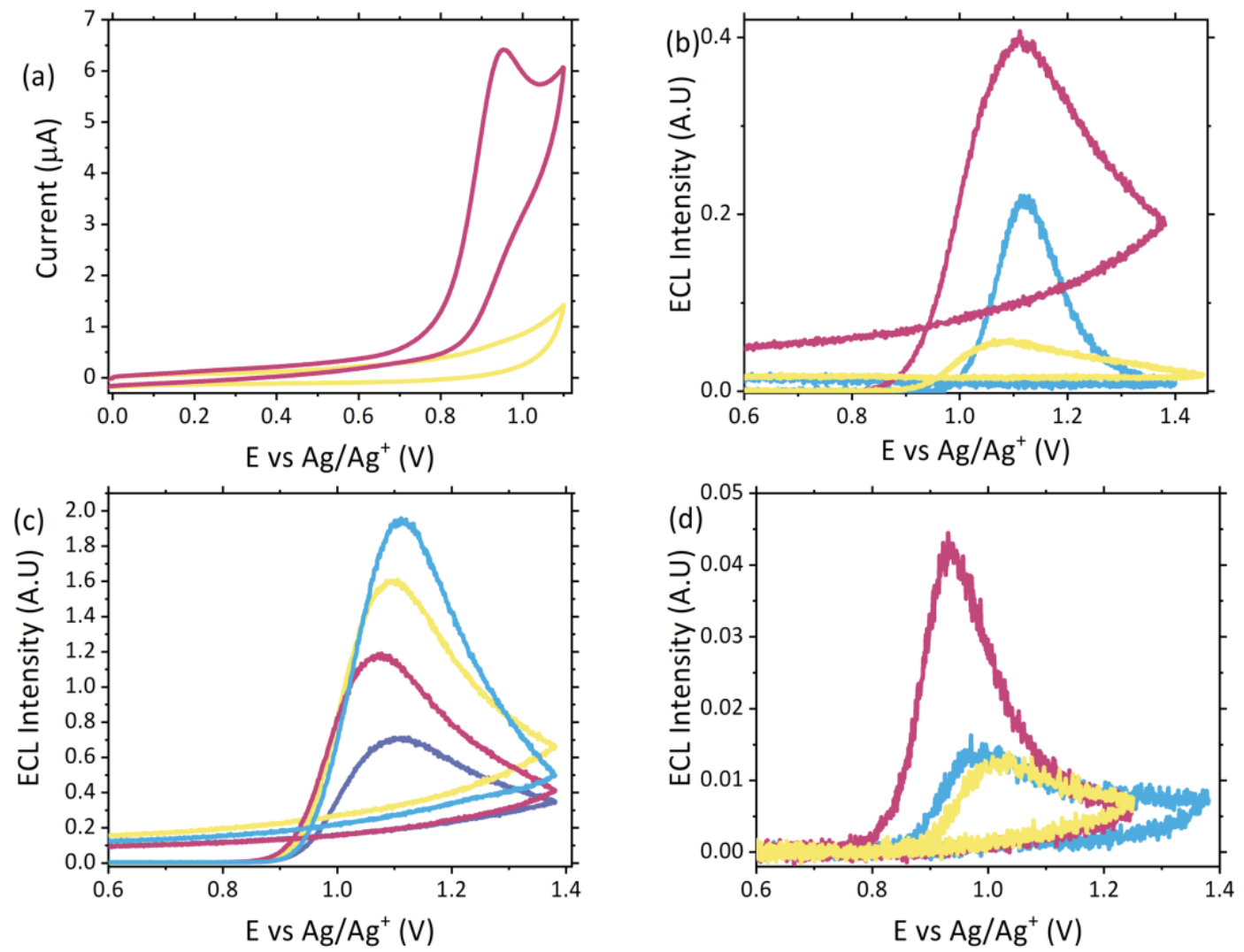

Figure 2. (a) $\mathrm{CV}$ of $100 \mu \mathrm{M}$ MDMA (pink) and $100 \mu \mathrm{M}$ MA (yellow), (b) ECL response of 50 $\mu \mathrm{M}$ MDMA (pink), MA (blue) and with no co-reactant (yellow) at $\left[\mathrm{Ru}(\mathrm{bpy})_{3}\right]^{2+}$ modified electrodes, (c) ECL intensity of $\left[\mathrm{Os}(\text { diars })_{2}(\mathrm{bthp})\right]^{2+}$ modified electrodes with MDMA at concentrations from $0 \mu \mathrm{M}$ (blue) to $100 \mu \mathrm{M}$ (purple) demonstrating the quenching of the ECL from this complex, and (d) ECL response for the $\left[\operatorname{Ir}(\mathrm{bt})_{2}(\mathrm{pt}-\mathrm{TEG})\right]^{+}$modified electrodes with no co-reactant (blue), $50 \mu \mathrm{M}$ MA (yellow) and $50 \mu \mathrm{M}$ MDMA (pink). All measurements were collected at a scan rate of 100 $\mathrm{mV} \mathrm{s}^{-1}$ with a supporting electrolyte of $1 \mathrm{M} \mathrm{LiClO}_{4}$.

To further assess the utilization of multiple luminophores for improved ECL selectivity, we examined two structurally related co-reactant species that exhibit more similar electrochemical behavior in the region of interest than MDMA and MA. Sister tropane alkaloids, atropine and scopolamine, differ in structure by the presence of the epoxide group on the tropane ring of scopolamine (Figure 3 (a)). Prior works have demonstrated the indistinguishable ECL emissions from these species upon testing with $\left[\mathrm{Ru}(\mathrm{bpy})_{3}\right]^{2+}$ based sensors. ${ }^{21,22,37}$

Comparable to the results with MA and MDMA, the encapsulated $\left[\operatorname{Ir}(\mathrm{bt})_{2}(\mathrm{pt}-\mathrm{TEG})\right]^{+}$provided greater selectivity than $\left[\mathrm{Ru}(\mathrm{bpy})_{3}\right]^{2+}$, with ECL generated in the presence of scopolamine (Figure 3 (b)), whereas the ECL response from atropine was indistinguishable from the blank. This apparent 
selectivity would again facilitate the detection of one co-reactant in the presence of the other. The unexpected findings of this initial proof-of-concept study has prompted further investigation into the greater selectivity offered by this and related iridium-based complexes over the conventional $\left[\mathrm{Ru}(\mathrm{bpy})_{3}\right]^{2+}$ luminophore. It is hoped that a thorough understanding of the mechanisms responsible for the differences in emission will facilitate the application of this methodology to array-based ECL screening applications. Initial studies suggest this apparent selectivity is governed by the inability of the iridium complex to behave as a mediator for oxidation. Previous analysis has demonstrated at concentrations of forensic relevance neither atropine nor scopolamine are oxidizable within the potential region interrogated. However, at higher concentrations (typically within the milli-molar range) oxidation of scopolamine is witnessed at the unmodified carbon paste electrode surface. Both MA and atropine therefore present with poorer electrochemistry within this region compared with their structurally related counter parts, scopolamine and MDMA, and as such the heterogenous oxidation product required for ECL is not produced for either MA or atropine. With the oxidation product of the co-reactant required to initiate the ECL mechanism, compounds that possess poor electroactive functionality are still seen to produce emission via a homogenous oxidation pathway with the luminophore complex, as described by the oxidative $N$-dealkylation process for atropine shown within scheme $1^{22}$ where the $\mathrm{Ru}(\mathrm{III})$ species acts as the mediator to produce the oxidized co-reactant. It is currently believed this mechanism of oxidation cannot proceed with the iridium-based complexes, and as such prevents luminescence from co-reactants with poor electroactive functionality. This hypothesis is furthered by the appearance of a small emission signal at higher atropine concentrations see Figure 3 (b), which have shown to display the peak corresponding to oxidation of the tropane alkaloid ring. ${ }^{22}$ 
Scheme 1. Mechanism of the oxidative $N$-dealkylation of atropine (a) leading to the formation of noratropine (e) and formaldehyde (f). ${ }^{22}$

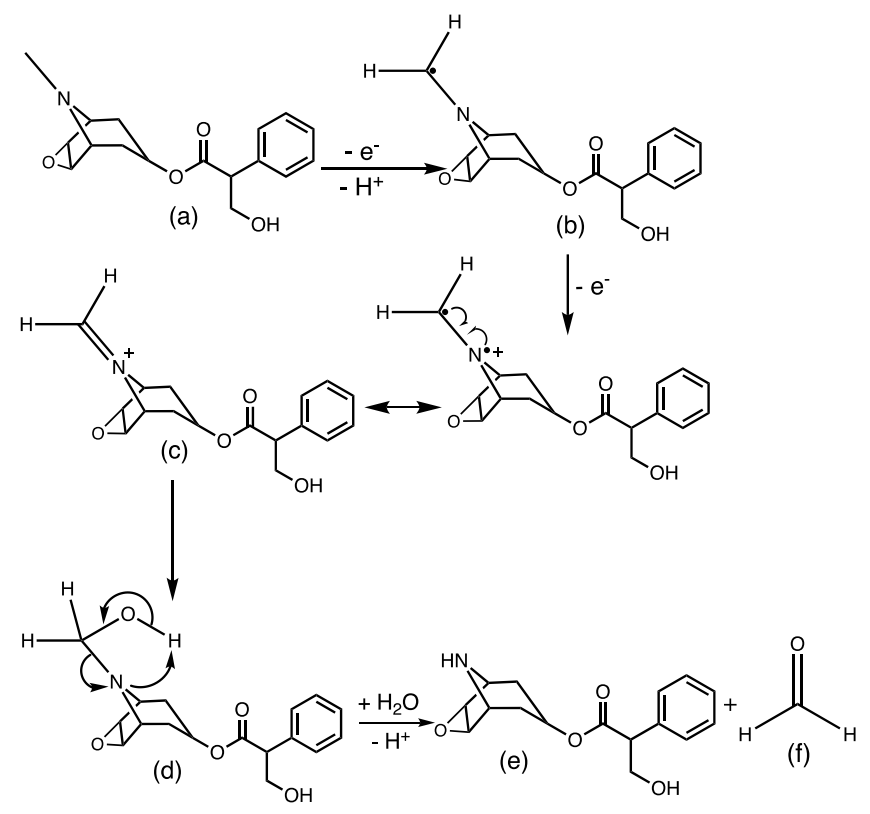

(a)
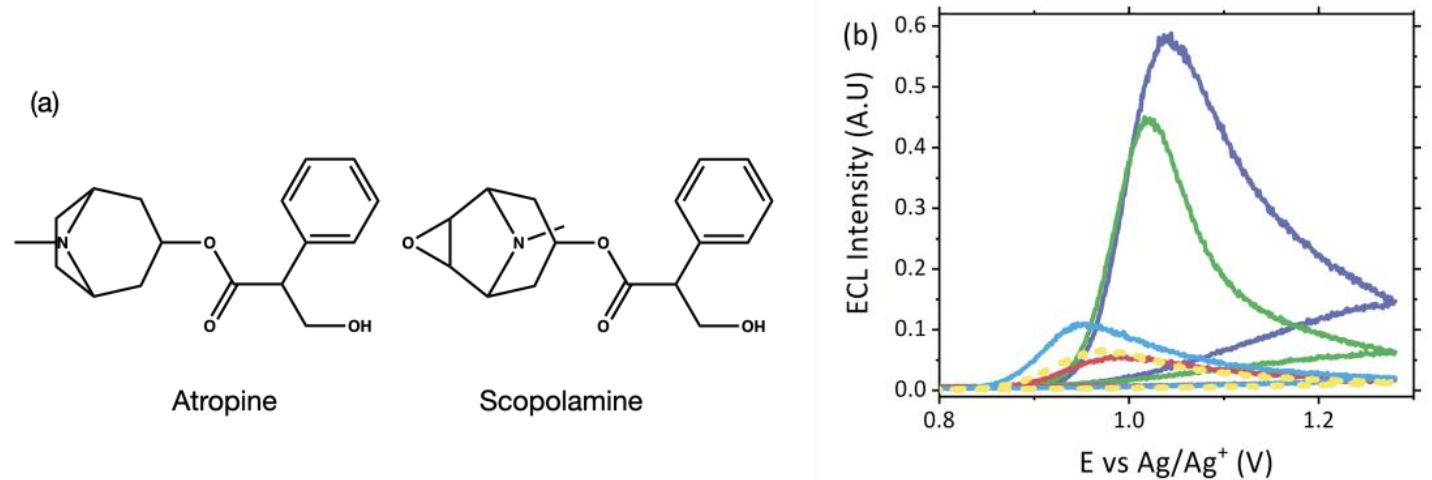

Figure 3. (a) Chemical structures of atropine and scopolamine and (b) ECL responses with no coreactant (yellow dash), $50 \mu \mathrm{M}$ and $100 \mu \mathrm{M}$ atropine (pink and blue, respectively) and $50 \mu \mathrm{M}$ and $100 \mu \mathrm{M}$ scopolamine (green and purple, respectively) using $\left[\operatorname{Ir}(\mathrm{bt})_{2}(\mathrm{pt}-\mathrm{TEG})\right]^{+}$modified electrodes at a scan rate of $100 \mathrm{mV} \mathrm{s}^{-1}$, across a potential range of 0.8 to $1.3 \mathrm{~V} \mathrm{vs} \mathrm{Ag} / \mathrm{Ag}^{+}$with a supporting electrolyte of $1 \mathrm{M} \mathrm{LiClO}_{4}$.

Interestingly, in the case of atropine and scopolamine, the $\left[\mathrm{Os}(\text { diars })_{2}(\mathrm{bthp})\right]^{2+}$ complex also provided a means by which to distinguish between these two compounds. Here atropine behaved as a quencher toward the osmium complex, whilst the presence of scopolamine increased the ECL 
intensity (Figure 4). It is again unclear as to the cause of this contrasting behavior toward this metal complex, despite the very similar chemical structure and electroactive functionality of the two species. It is hoped further investigation into the mechanisms of these ECL processes will provide a thorough understanding as to the source of the selectivity, ultimately leading to the opportunity to exploit these behaviors for the development of targeted multi-metal luminophore arrays. Moreover, the combination of different metal complexes presents the opportunity to exploit their distinctive emission colors in order to provide a viable colorimetric ECL screening method void of the subjectivity of presumptive tests.
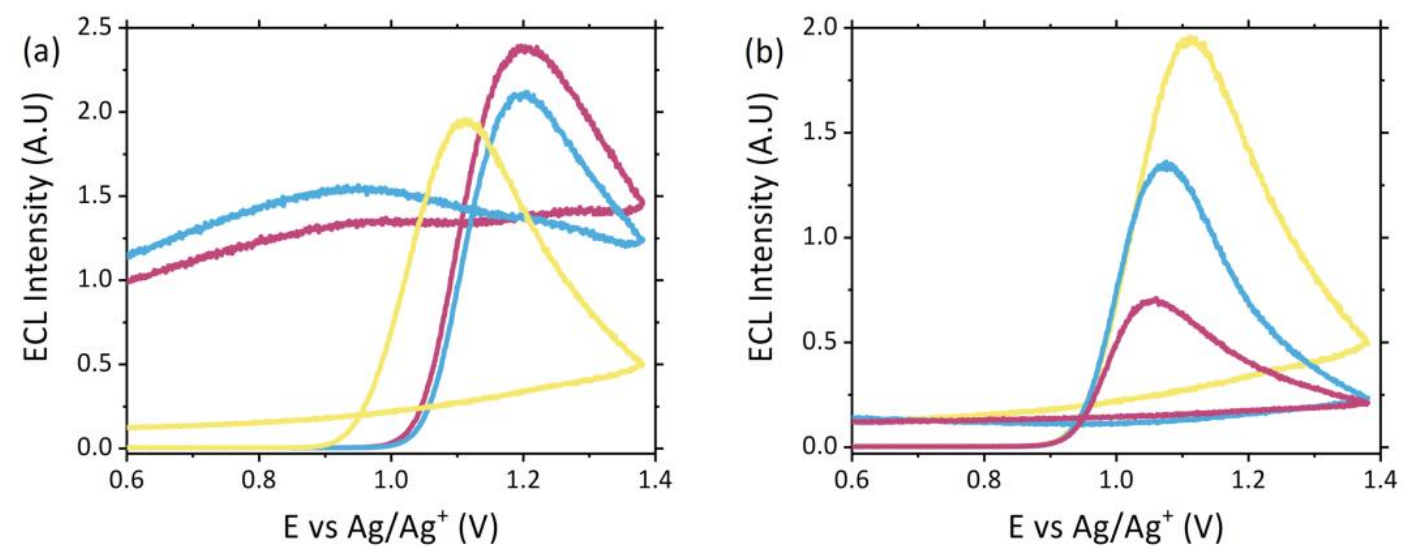

Figure 4. ECL responses with (a) no co-reactant (yellow), $50 \mu \mathrm{M}$ scopolamine (blue) and $100 \mu \mathrm{M}$ scopolamine (pink) and (b) no co-reactant (yellow), $50 \mu \mathrm{M}$ atropine (blue) and $100 \mu \mathrm{M}$ atropine (pink) using $\left[\mathrm{Os}(\text { diars })_{2}(\mathrm{bthp})\right]^{2+}$-modified electrodes at a scan rate of $100 \mathrm{mV} \mathrm{s}^{-1}$, across a potential range of 0.6 to $1.38 \mathrm{~V}$ vs $\mathrm{Ag} / \mathrm{Ag}^{+}$with a supporting electrolyte of $1 \mathrm{M} \mathrm{LiClO}_{4}$.

It is clear that alternative metal luminophores hold the potential to improve ECL selectivity. In this format, this methodology could be used to distinguish scopolamine or atropine in simple matrices such as seized drug samples, based upon the emission properties with either the iridium or osmium complex. However, whilst the complexes are used as individual luminophores, the approach is insufficient to identify either tropane alkaloid or multiple alkaloids in complex matrices. 


\section{Conclusions}

This contribution has demonstrated the potential for ECL based sensors for employment as screening strategies for the detection and differentiation of drug species. ECL has long been used to detect various drugs, placing it well as a viable alternative for current screening methodologies. However, the intrinsic lack of selectivity offered by ECL has limited its application within this field. Here we have shown how the employment of different metal luminophores can be considered in combination to provide superior selectivity between closely related compounds. The encapsulated luminophore approach is well-suited to the development of ECL sensor arrays, where the signals of numerous ECL sensors could be simultaneously examined. Although this proof-of-concept study has shown promise for the employment of such a methodology, further research is required to gain a thorough understanding of the light producing and quenching pathways that gives these metal complexes their observed selectivities, in addition to the exploration of ECL array formats and how they can be employed within commercial sensing systems. Here, a physiological relevant $\mathrm{pH}$ of 7 was chosen due to the planned progression of this research into point-of-care biosensor applications. With the dependance upon the co-reactant and its dissociation mechanism influencing the relationship between ECL intensity and system $\mathrm{pH}$, amine species are widely accepted to exhibit comparable relationships as a result of their similar structural properties. ${ }^{11,21,35,37,70}$ As such, the metal luminophore choice is largely independent of $\mathrm{pH}$ effects, with the co-reactants $\mathrm{pKa}$ dictating where maximum ECL intensities are observed. ${ }^{11,21,35,37,65,70}$ Prior research has identified $\mathrm{pH} 8$ as the optimum $\mathrm{pH}$ for the ECL analysis of ATS and tropane alkaloids as well as a number of additional amine species. ${ }^{11,21,35,37,70}$ Although the optimum $\mathrm{pH}$ of these species is largely consistent variations in ECL intensity at the lower $\mathrm{pH}$ ranges do present the opportunity to exploit these differences to further improve sensor specificity. ${ }^{21}$ Previously we have coined $\mathrm{pH}$-controlled ECL which exploits this characteristic for the differentiation of atropine and scopolamine with the $\left[\mathrm{Ru}(\mathrm{bpy})_{3}\right]^{2+}$ luminophore. ${ }^{21}$ As such, it is hoped that expansion of $\mathrm{pH}$-controlled ECL paired with the selectivity offered by different metal luminophores, as displayed within this contribution, will further the development of multi-luminophore sensing systems, ultimately enhancing the possibility of the employment of ECL within the biomedical field. 


\section{Acknowledgments}

The authors would like to thank the Carnegie Trust for the Universities of Scotland for finically supporting this work, through provision of a $\mathrm{PhD}$ scholarship. They would also like to extend their thanks to the Royal Society of Chemistry for provision of the Mobility Grant (RM1802-1666) which made the research visits and collaboration with Deakin University possible. All data underpinning this publication are openly available from the University of Strathclyde KnowledgeBase https://doi.org/10.15129/3c4b895a-a663-4c55-9dc4-37bcd2078aa8.

\section{References}

1. United Nations Publication, World Drug Report 2018, https://www.unodc.org/wdr2018/prelaunch/WDR18_Booklet_1_EXSUM.pdf, (accessed 9th October, 2018).

2. L. Shaw and L. Dennany, Curr. Opin. Electrochem., 2017, 3, 23-28.

3. J. Tettey and C. Crean, Philos. Trans. R. Soc., B, 2015, 370, 20140265.

4. O. Beck, L. Rausberg, Y. Al-Saffar, T. Villen, L. Karlsson, T. Hansson and A. Helander, Drug Test. Anal., 2014, 6, 492-499.

5. M. Fagiola, T. Hahn and J. Avella, J. Anal. Toxicol., 2018, 42, 562-569.

6. K. E. Grafinger, M. E. Liechti and E. Liakoni, Br. J. Clin. Pharmacol, , 2019, DOI: 10.1111/bcp.14115.

7. A. Helander, M. Bäckberg, P. Hultén, Y. Al-Saffar and O. Beck, Forensic Sci. Int., 2014, 243, 23-29.

8. W. Miao, Chem. Rev., 2008, 108, 2506-2553.

9. M. M. Richter, Chem. Rev., 2004, 104, 3003-3036.

10. C. K. P. Truong, T. D. D. Nguyen and I.-S. Shin, BioChip J., 2019, 13, 203-216.

11. J. McGeehan and L. Dennany, Forensic Sci. Int., 2016, 264, 1-6.

12. E. J. O'Reilly, P. J. Conroy, S. Hearty, T. E. Keyes, R. O'Kennedy, R. J. Forster and L. Dennany, RSC Adv., 2015, 5, 67874-67877.

13. Z. Mohsan, A. L. Kanibolotsky, A. J. Stewart, A. R. Inigo, L. Dennany and P. J. Skabara, J. Mater. Chem. C, 2015, 3, 1166-1171.

14. C. Ma, Y. Cao, X. Gou and J.-J. Zhu, Anal. Chem., 2019, 92, 431-454.

15. A. Zanut, A. Fiorani, S. Rebeccani, S. Kesarkar and G. Valenti, Anal. Bioanal. Chem., 2019, 411, 4375-4382.

16. B. Babamiri, D. Bahari and A. Salimi, Biosens. Bioelectron., 2019, 142, 111530.

17. L. Hu, Y. Wu, M. Xu, W. Gu and C. Zhu, Chem. Comm., 2020, 56, 10989-10999.

18. A. Zanut, A. Fiorani, S. Canola, T. Saito, N. Ziebart, S. Rapino, S. Rebeccani, A. Barbon, T. Irie and H.-P. Josel, Nature communications, 2020, 11, 1-9.

19. S. Voci, R. Duwald, S. Grass, D. J. Hayne, L. Bouffier, P. S. Francis, J. Lacour and N. Sojic, Chem. Sci., 2020, 11, 4508-4515.

20. K. G. Cho, J. I. Lee, S. Lee, K. Hong, M. S. Kang and K. H. Lee, Advanced Functional Materials, 2020, 1907936. 
21. K. Brown, C. Jacquet, J. Biscay, P. Allan and L. Dennany, Anal. Chem., 2020, 92, 2216-2223.

22. K. Brown, M. McMenemy, M. Palmer, M. J. Baker, D. W. Robinson, P. Allan and L. Dennany, Anal. Chem., 2019, 91, 12369-12376.

23. G. J. Barbante, E. H. Doeven, E. Kerr, T. U. Connell, P. S. Donnelly, J. M. White, T. Lópes, S. Laird, D. J. D. Wilson, P. J. Barnard, C. F. Hogan and P. S. Francis, Chemistry - A European Journal, 2014, 20, 3322-3332.

24. L. C. Soulsby, D. J. Hayne, E. H. Doeven, D. J. D. Wilson, J. Agugiaro, T. U. Connell, L. Chen, C. F. Hogan, E. Kerr, J. L. Adcock, P. S. Donnelly, J. M. White and P. S. Francis, Phys. Chem. Chem. Phys., 2018, 20, 18995-19006.

25. L. C. Soulsby, J. Agugiaro, D. J. D. Wilson, D. J. Hayne, E. H. Doeven, L. Chen, T. T. Pham, T. U. Connell, A. J. Driscoll, L. C. Henderson and P. S. Francis, ChemElectroChem, 2020, 7, 1889-1896.

26. L. M. Quan, B. D. Stringer, M. A. Haghighatbin, J. Agugiaro, G. J. Barbante, D. J. D. Wilson, C. F. Hogan and P. J. Barnard, Dalton Trans., 2019, 48, 653-663.

27. D. Bruce and M. M. Richter, Anal. Chem., 2002, 74, 1340-1342.

28. K. N. Swanick, M. Sandroni, Z. Ding and E. Zysman-Colman, Chemistry - A European Journal, 2015, 21, 7435-7440.

29. M. R. Moghaddam, S. Carrara and C. F. Hogan, Chem. Comm., 2019, 55, 10241027.

30. H. c. D. Abruña, J. Electrochem. Soc., 1985, 132, 842.

31. G. Angulo, A. Kapturkiewicz, S.-Y. Chang and Y. Chi, Inorg. Chem. Commun., 2009, 12, 378-381.

32. I. Bist, B. Song, I. M. Mosa, T. E. Keyes, A. Martin, R. J. Forster and J. F. Rusling, ACS Sensors, 2016, 1, 272-278.

33. L. Jianguo, C. Yuan and J. Huangxian, Electroanalysis, 2007, 19, 1569-1574.

34. Q. Song, G. M. Greenway and T. McCreedy, Analyst, 2001, 126, 37-40.

35. X.-Y. Yang, C.-Y. Xu, B.-Q. Yuan and T.-Y. You, Chin. J. Anal. Chem., 2011, 39, 1233-1237.

36. A. Zhang, C. Miao, H. Shi, H. Xiang, C. Huang and N. Jia, Sens. Actuators B, 2016, 222, 433-439.

37. K. Brown, C. Jacquet, J. Biscay, P. Allan and L. Dennany, Analyst, 2020, 145, 4295-4304.

38. Y. Yang, S. Zhai, C. Liu, X. Wang and Y. Tu, ACS Omega, 2019, 4, 801-809.

39. Q. Cai, L. Chen, F. Luo, B. Qiu, Z. Lin and G. Chen, Anal. Bioanal. Chem., 2011, 400, 289-294.

40. E. Guler, G. Bozokalfa, B. Demir, Z. P. Gumus, B. Guler, E. Aldemir, S. Timur and H. Coskunol, Drug Test. Anal., 2017, 9, 578-587.

41. J. C. Vidal, J. R. Bertolín, L. Bonel, L. Asturias, M. J. Arcos-Martínez and J. R. Castillo, Electroanalysis, 2016, 28, 685-694.

42. Y. Xu, X.-B. Yin, X.-W. He and Y.-K. Zhang, Biosens. Bioelectron., 2015, 68, 197203.

43. L. Gao, H. Wang, Z. Deng, W. Xiang, H. Shi, B. Xie and H. Shi, New J. Chem., 2020, 44, 2571-2577.

44. Y. Zhao, X.-W. He and X.-B. Yin, Chem. Comm., 2011, 47, 6419-6421.

45. Y. Du and E. Wang, Electroanalysis: An International Journal Devoted to Fundamental and Practical Aspects of Electroanalysis, 2008, 20, 643-647.

46. L. Dennany, E. J. O’Reilly, T. E. Keyes and R. J. Forster, Electrochem. Commun., 2006, 8, 1588-1594. 
47. K. Mariño, R. Saldova, B. Adamczyk and P. M. Rudd, in Carbohydrate Chemistry: Volume 37, The Royal Society of Chemistry, 2012, vol. 37, pp. 57-93.

48. J. Perła-Kaján, T. Twardowski and H. Jakubowski, Amino Acids, 2007, 32, 561572.

49. H. Xie, X. Li, L. Zhao, L. Han, W. Zhao and X. Chen, Sens. Actuators B, 2016, 222, 226-231.

50. H. Hosono, W. Satoh, J. Fukuda and H. Suzuki, Sens. Actuators B, 2007, 122, 542548.

51. B. Carlson, B. E. Eichinger, W. Kaminsky, J. P. Bullock and G. D. Phelan, Inorg. Chim. Acta, 2009, 362, 1611-1618.

52. L. Chen, D. J. Hayne, E. H. Doeven, J. Agugiaro, D. J. D. Wilson, L. C. Henderson, T. U. Connell, Y. H. Nai, R. Alexander, S. Carrara, C. F. Hogan, P. S. Donnelly and P. S. Francis, Chem. Sci., 2019, 10, 8654-8667.

53. Z. M. Smith, E. Kerr, E. H. Doeven, T. U. Connell, N. W. Barnett, P. S. Donnelly, S. J. Haswell and P. S. Francis, Analyst, 2016, 141, $2140-2144$.

54. E. M. Kober, B. P. Sullivan, W. J. Dressick, J. V. Caspar and T. J. Meyer, J. Am. Chem. Soc., 1980, 102, 7383-7385.

55. M. Akhoundian, T. Alizadeh, M. R. Ganjali and P. Norouzi, Talanta, 2019, 200, 115-123.

56. C.-A. Bartlett, S. Taylor, C. Fernandez, C. Wanklyn, D. Burton, E. Enston, A. Raniczkowska, M. Black and L. Murphy, Chem. Cent. J., 2016, 10, 3.

57. R. A. S. Couto, S. S. Costa, B. Mounssef, J. G. Pacheco, E. Fernandes, F. Carvalho, C. M. P. Rodrigues, C. Delerue-Matos, A. A. C. Braga, L. Moreira Gonçalves and M. B. Quinaz, Sens. Actuators B, 2019, 290, 378-386.

58. C. Han, Z. Shang, H. Zhang and Q. Song, Anal. Methods, 2013, 5, 6064-6070.

59. F. Takahashi, S. Nitta, R. Shimizu and J. Jin, Forensic Tox., 2018, 36, 185-191.

60. J. L. Adcock, C. J. Barrow, N. W. Barnett, X. A. Conlan, C. F. Hogan and P. S. Francis, Drug Test. Anal., 2011, 3, 145-160.

61. J. Sun, X. Xu, C. Wang and T. You, ELECTROPHORESIS, 2008, 29, 3999-4007.

62. E. Dokuzparmak and L. Dennany, Electrochemiluminescence detection of methamphetamine in biological matrices, SPIE, 2020.

63. N. S. Pennington, M. M. Richter and B. Carlson, Dalton Trans., 2010, 39, 15861590 .

64. E. M. Zammit, G. J. Barbante, B. Carlson, E. H. Doeven, N. W. Barnett, C. F. Hogan, M. M. Richter and P. S. Francis, Analyst, 2012, 137, 2766-2769.

65. D. Bruce, M. M. Richter and K. J. Brewer, Anal. Chem., 2002, 74, 3157-3159.

66. L. Bouffier and N. Sojic, in Analytical Electrogenerated Chemiluminescence: From Fundamentals to Bioassays, The Royal Society of Chemistry, 2020, DOI: 10.1039/9781788015776-00001, pp. 1-28.

67. Z. Liu, W. Qi and G. Xu, Chem. Soc. Rev., 2015, 44, 3117-3142.

68. T. H. Fereja, F. Du, C. Wang, D. Snizhko, Y. Guan and G. Xu, Journal of Analysis and Testing, 2020, 4, 76-91.

69. X. Zhang, C. Chen, J. Li, L. Zhang and E. Wang, Anal. Chem., 2013, 85, 53355339.

70. A. Zhang, C. Miao, H. Shi, H. Xiang, C. Huang and N. Jia, Sens. Actuators B, 2016, 222, 433-439. 
